complex did not descend at all below the iso-electrical level, being entirely of $R$ type, and for the first time the $T$ wave was easily identified as positive in character. In Lead II the $T$ wave was less steeply inverted, while in Lead III it remained much the same.

On December 30th in Lead I there was a frank upward $R$ wave of a voltage of $4 \mathrm{~mm}$., but a wave which was slurred in its downward stroke; the $T$ wave was still erect but its voltage had doubled. In Lead II for the first time the $T$ wave was positive; but the $T$ wave in Lead III remained inverted, and the curve in that lead was practically identical with that of eighteen days previously.

The patient made a clinical recovery, and a few days later left for Cornwall.

\section{PROLAPSE OF THE RECTUM IN CHILDREN.} BY

IAN FRASER, M.CH., F.R.C.S., ASSISTANT SURGEON, BELFAST HOSPITAL FOR SICK CHILDREN.

ONE cannot attend a children's hospital without being struck by the large number of children who suffer from prolapse of the rectum. No definite treatment is prescribed, and yet apparently these patients cease to return after some time; presumably there has been a spontaneous (ure. On referring to the usual textbooks on this subject one finds first the instruction " remove the cause," and yet how scldom one finds a cause.

\section{Etiology}

Constipation is blamed, and with it the straining at stool that is required to expel the solid motion. Diarrhoea has its adrocates, on account of the irritation it produces. For a similar reason, worms, polyps, adenomata, and piles are responsible according to others; these, by producing a feeling of fullness in the rectum, would certainly tend to provoke a constant desire to defaecate. An invisible fissure and a svmptomless pruritus are often blamed. When a possible cause cannot be found in the anal region recourse is made to some other part; a tight foreskin, a balanitis, or a pin-hole meatus is carefully looked for. Nrentually it is said that the real cause is that there is a deficiency of fat in the ischio-rectal fossa, so that the rectum has lost its natural support. On this assumption the condition is similar to that obtained when the perinephric fat is diminished, so that as an analogy we might speak of the condition as a " movable or floating rectum."

The last so-called cause is probably the least likely of all. A close examination of a few of the cases will soon demonstrate that a prolapsus ani is not a prolapse of the anus, but at first of the mucous membrane through the anus. In the early cases the muscle wall of the rectum bears its normal relation to the ischio-rectal fat. Two definite changes exist in the average case : first, the anus is patulous - the examining finger can enter with ease and is not gripped by the sphincter as in a healthy case; and secondly, the mucous membrane has apparently lost its close grip upon the muscle wall, and instead of adhering is carried down with the motion.

\section{Treatment.}

As regards treatment, one first looks for a possible cause, and this in the majority of cases is non-existent. Many of the patients are fine, rosy-cheeked, sturdy children; they have regular bowels, have lost no fat recently, and are free from worms, polyps, etc. Having treated the mythical cause, something must be done for the child while he is actually at stool. In some cases the motion is passed in the squatting position, or on the side, and between times the buttocks are held together with strapping. Judging from the fact that patients thus treated stop attending eventually, we must conclude that this method is satisfactory and that in time a cure does result from it; but during that time considerable pain and discomfort must be endured.

I have written this short note with the object of advocating treatment by the injection of absolute alcohol. I have adopted this method in about fifty cases, and cure. has followed in all of them. In nine cases out of ten this result has been brought about by one injection ; in resistant cases a second injection has invariably been effective. The treatment is not new, but is, I think, insufficiently appre- ciated; the technique is so simple and the result so good that it is worth trying. The injection of the alcohol stimulates the anus to contract and at the same time produces a fibrosis and adhesion between mucous membrane and muscle.

The procedure is as follows: Without any previous treatment to the bowel the patient is given a general anaesthetic and placed in the lithotomy position. The surgeon places his left index finger in the rectum, and using a $1 \mathrm{c.cm}$. glass syringe with a fine Record needle, $1 \frac{1}{2}$ inches long, he passes the needle through the muco-cutaneous junction along the interval between the mucous membrane and the muscle coat. The injection is made as the needle is withdrawn. Four injections are given at one sitting-in front, at the back, and at each side-the total amount of alcohol used being $1 \mathrm{c.cm}$.-in other words, $1 / 4 \mathrm{c.cm}$. at each of the four points. The operation can be completed in five minutes. The buttocks are then strapped for one day, and the bowels are opened in twenty-four to thirty-six hours. The advantages of this method are that the condition is cured immediately in 80 per cent. of the cases at one sitting, and although the discomfort is greater for twentyfour hours, there is not the summation of pain that the child would otherwise suffer.

In conclusion, prolapse of the rectum is a common and distressing complaint, spontaneously curable in most cases, but reacting readily to a simple minor operation which will save weeks and months of discomfort A modified technique has been rery successful in adults, using novocain instead of a general anaesthetic for the operation itself, and giving some 40 per cent. antipyrin to diminish after-pain.

\section{Atlemoranda: MEDICAL, SURGICAL, OBSTETRICAL.}

\section{PATENT BRANCHIAL CLEFT. \\ (With Special Plate.)}

THe case of W. R. C., aged 24 years, presenting a certain feature of interest, appears worth reporting.

This man presented himself with a sinus situated 1 inch above the sternal insertion of the right sterno-mastoid muscle and at its anterior border, which discharged a clear fluid. At the orifice were situated three minute hairs. On injection of the "sinus" with iodoform emulsion the patient complained of sickly sensations in his throat, when examination of the fauces revealed the emulsion lying in the right supra-tonsillar fossa. $X$-ray photographs confirmed the extent of the fistula. In the photographs there appear vague shadows at the level of the disc between the 5 th and 6 th cervical bodies, suggesting lateral prolongations from the main fistula. It has been impossible to confirm these.

It is significant that the man first became aware of his condition following a right-sided quinsy, when the "pimple" commenced to discharge what was then a yellow fluid:

Penzance.

$$
\text { Anthony H. G. Johns, M.A., M.B., B.Ch., }
$$

\section{CONGENITAL DYSTROPHY OF THE NAILS.} (With Special Plate.)

As congenital drstrophy of the nails is comparatively uncommon I thought the following case should be placed on record.

A healthy girl, aged 16 years, was sent to see me with reference to the condition of her finger-nails. Her occupation was that of a domestic, and she said the condition had been present as long as she could remember, but recently the nails worried her by their look and interfered with her work. On examination there was a distinct horny ridge in the mid-line of the dorsum on the nail plates of the middle two digits of both hands, as well as a similar condition of the index finger of the left hand. At the bases of the affected nails the peri-unguinal tissue was raised, but there was ro sign of any tenderness. From 